\title{
Exercícios de inatualidade. As Considerações extemporâneas como ontologia crítica*
}

\author{
Gianfranco Ferraro**
}

Resumo: As quatro Considerações extemporâneas de Nietzsche estão entre os escritos mais negligenciados do autor. Porém, elas constituem o êxito de um projecto inserido numa época crucial do desenvolvimento de Nietzsche como filósofo. A partir, em particular, de uma análise das questões postas na primeira, David Strauss, o devoto e o escritor e na terceira, Schopenhauer como educador, tentar-se-á mostrar duas perspectivas filosóficas que, iniciadas nas Considerações, acompanharão o percurso de Nietzsche até o fim: a de uma "ontologia da atualidade", segundo a expressão de Foucault, e a de uma filosofia como "maneira de viver", segundo a expressão de Hadot.

Palavras-Chave: Extemporânea, crítica, atualidade, exercícios espirituais, Foucault.

* Desejo agradecer Vanessa Rola pela sua paciência na revisão deste texto.

** Pós-doutorando no Instituto de Filosofia da Nova (IFILNOVA - FCSH),

Universidade Nova de Lisboa, Lisboa, Portugal.

ORCID https://orcid.org/0000-0003-4449-6127

Correio eletrônico: gianfranco.ferraro@gmail.com

92 | Cad. Nietzsche, Guarulhos/Porto Seguro, v.40, n.1, p. 92-123, janeiro/abril, 2019. 
No seu livro sobre Nietzsche, Bataille esclarece como a filosofia deste autor está intimamente ligada a uma experiência de vida: "não se entendeu uma palavra da obra de Nietzsche antes de ter vivido essa dissolução fulgurante na totalidade; fora disso, essa filosofia não passa de um dédalo de contradições...". ${ }^{1}$ Um pouco mais adiante, depois de ter sublinhado como a forma de vida do espírito livre é aquela da ascese, ou aquela do jogo, Bataille acrescenta: "As doutrinas de Nietzsche têm isto de estranho: não se pode segui-las". ${ }^{2}$ A interpretação de Bataille, pela sua influência na abordagem que outros autores fizeram de Nietzsche em França, entre os anos 60 e 70, constitui uma referência crucial quando se tenta abordar as diferentes formas de escrita filosóficas de Nietzsche, não só em termos historiográficos, mas também a partir da ligação entre a palavra escrita e o carácter da "filosofia" que o autor quer atravessar. Por outro lado, Bataille defende como a experiência filosófica de Nietzsche não pode ser directamente ligada a uma noção orientativa da existência. Ser "seguidor" de Nietzsche não significaria interpretar o seu desenho filosófico, como que atravessar a mesma experiência filosófica que se traduz nos seus escritos, sem que isto pudesse ter a ver com uma qualquer vontade de ação consequente: "Percebida sob as perspectivas da ação, a obra de Nietzsche é um aborto - dos mais indefensáveis -, sua vida um fracasso, assim como a de quem tenta pôr em prática seus escritos". ${ }^{3}$ É nesse sentido que se abre a possibilidade de ler as Considerações extemporâneas a partir de autores como Foucault e Hadot, ligados de maneira direta a uma abordagem do pensamento nietzschiano que tenta questionar, na linha iniciada por Bataille, o sentido não só teórico, mas também recreativo, da própria forma de pensar, da prática nietzschiana, isto é, da filosofia.

\footnotetext{
1 Georges Bataille, 2017, p. 31.

2 Georges Bataille, 2017, p. 125.

3 Georges Bataille, 2017, p. 31.
} 
Ferraro, G.

Uma prática "autogenealógica", 4 que tem como alvo a transformação da relação do filósofo consigo próprio e com a sua própria época.

Entre os escritos nos quais Nietzsche enfrenta de maneira mais direta a sua época, as quatro Considerações extemporâneas ocupam uma posição particular. ${ }^{5}$ Por duas razões principais: antes de mais, pelo lugar que ocupam na biografia de Nietzsche e, em segundo lugar, pela forma como fazem parte do próprio projeto de escrita. A intenção do jovem filósofo - quando Nietzsche as concebe, em 1873, não tinha ainda trinta anos - era a de enfrentar, de forma crítica, problemas específicos da sua atualidade, ou figuras de intelectuais em particular, através dos quais teria sido possível, para si, esclarecer a sua posição de intelectual contemporâneo. Todos os quatro ensaios efetivamente publicados no final, dos vários que Nietzsche tinha planeado, são escritos polêmicos, isto é, escritos em que Nietzsche quer julgar, quase apresentando-o diante de um tribunal, o tempo presente, a sua própria época, com o objetivo de destacar as inconsistências, as fraquezas, as aporias. ${ }^{6}$

4. Cf. Antonio Edmilson Paschoal, 2015, p. 27-44.

5 Vale a pena lembrar a forma pela qual foi traduzido o alemão "Unzeitgemässe" em algumas línguas decisivas para o desenvolvimento da Nietzscheforschung : "intempestivas" em português de Portugal, "inattuali" em italiano, "inactuelles" em francês, "untimely" em inglês. Em língua portuguesa não temos, infelizmente, uma tradução crítica de referência. Os vários excertos serão, portanto, apresentados a partir da tradução do original alemão, tendo em conta algumas opções disponibilizadas, em particular, da tradução italiana editada por Giorgio Colli e Mazzino Montinari. Nessa edição, David Strauss, o devoto e o escritor é traduzido por Sossio Giametta, assim como Da utilidade e desvantagem da história para a vida e Richard Wagner em Bayreuth; Schopenhauer como educador é traduzido por Mazzino Montinari. No título deste ensaio tentei renforçar a componente de "inatualidade" presente na tradução italiana e francesa, onde o confronto com o "presente", com a atualidade, é particularmente evidente.

$6 \mathrm{Um}$ dos vários projectos planeados pelo jovem Nietzsche, como refere também D. Breazeale na sua introdução à tradução inglesa, compreende 13 escritos ( $c f$. NIETZSCHE, Friedrich. Untimely Meditations. Ed. by D. Breazeale, Cambridge: Cambridge University Press, 2012, pp. XI-XII). Na verdade, encontramos nos escritos posteriores, a partir de 1872, até 1876, uma extensa variedade de títulos, que nos permite perceber também a complexidade do projeto, assim como a própria aposta de Nietzsche numa forma de escrita de curtos ensaios. É preciso destacar como a última Consideração, Richard Wagner em Bayreuth, de 1876, pertence já a uma época biográfica e intelectual de Nietzsche diferente das outras três: nesse sentido, a leitura dos fragmentos posteriores desta altura torna-se particularmente importante. Para a ideia abrangente das reacções dos contemporâneos de Nietzsche

94 | Cad. Nietzsche, Guarulhos/Porto Seguro, v.40, n.1, p. 92-123, janeiro/abril, 2019. 
Exercícios de inatualidade. As Considerações extemporâneas como...

Todos eles constituem uma recuperação, nem sequer muito dissimulada, do gênero antigo da invectiva, ou do gênero moderno do pamphlet ${ }^{7}$. Por outro lado, as Considerações - as primeiras três em particular, mas também a última - situam-se numa encruzilhada biográfica da vida intelectual de Nietzsche, que, abandonando progressivamente as aspirações do jovem filólogo wagneriano, irá começar em breve o percurso que o levará a rejeitar os próprios pressupostos da sua fé de juventude, para abraçar a nova "profissão" de filósofo. ${ }^{8}$ Nas Considerações vemos, portanto, delinear-se já esta passagem: Nietzsche parece mobilizar a atenção adquirida no campo da filologia para aplicá-la à análise crítica da sua época e à "psicologia", com a qual, noutro momento, identificará a filosofia tout court. Podemos aqui descobrir, talvez, a lenta afirmação de uma fidelidade à sua tarefa, que parece constituir uma figura permanente também nas viragens teóricas seguintes. Nietzsche concebe a sua tarefa a partir da urgência de não fazer concessões relativamente ao seu próprio tempo, de libertar o seu horizonte cultural, e, portanto, libertar-se a si mesmo, pelo menos das "atitudes" da modernidade que se deslocam, no seu entendimento, para um beco sem saída. A partir deste momento surge, como escreve Fink num texto de certa forma ultrapassado mas nem por isso não menos crucial nos dias de hoje, "uma renúncia a tudo aquilo que até então era considerado como 'sagrado', ‘bom', “verdadeiro"”. A crítica da cultura, e até do

à publicação das Extemporâneas, $c f$. Hauke Reich, 2013, pp. 275ss. Como escreve Breazeale na sua introdução, as Considerações estão entre as obras mais negligenciadas de Nietzsche (p. VII). Contudo, vale a pena assinalar alguns estudos recentes: H. Schmidt, 2000; Giorgio Penzo, 2001; Annalisa Caputo, 2018.

7 É o próprio Nietzsche a oferecer esta interpretação em Ecce homo, como esclarecido mais abaixo.

8 Nietzsche dedica particular atenção, em Schopenhauer como educador, à questão do Beruf como "profissão vocacional". Num duplo sentido, "profissão" e "vocação", bem presente a um autor, como Nietzsche, educado segundo uma tradição cultural luterana, e que entra, por exemplo, na noção de "Lebensberufen", que Nietzsche destaca num fragmento de 1875, em relação a superficialidade na escolha de vida: "Quando cada um tem o seu objetivo num outro, ninguém tem objetivo na existência". Cf. Nachlass/FP 1875, 3[64] KSA 8.32 .

Cad. Nietzsche, Guarulhos/Porto Seguro, v.40, n.1, p. 92-123, janeiro/abril, 2019. 
Ferraro, G.

passado da filosofia, deverá ser feita através de instrumentos novos. É o próprio conjunto de regras dos seus interlocutores que Nietzsche recusa na sua batalha.

A critica nietzschiana do passado é conduzida numa linha da frente mais ampla. Nietzsche não combate só a filosofia tradicional, mas também a moral e a religião tradicionais. A sua luta tem a forma duma crítica que pertence a toda a cultura. [...] $\mathrm{O}$ fato da crítica nietzschiana afetar a cultura esconde facilmente a questão essencial, ou seja, que para Nietzsche trata-se só de uma contraposição filosófica à metafisica ocidental.9

Os sintomas da crise de época da qual Nietzsche, no Crepúscolo dos Ídolos, se tornará, muito tempo depois, um minucioso "auscultador", 10 devem, portanto, ser lidos como aquilo que são: figuras, alertas, nesgas de luz que permitem a análise de uma paisagem mais ampla. Procurar estas figuras, assinalar as fraturas da história, tudo isto se torna para o jovem filólogo a tarefa a perseguir, a própria imagem, que nunca mais será revogada, de um Beruf, nessa altura ainda incerto. Um Beruf que se configura já em termos críticos. Mais importante ainda, revela-se à luz do itinerário seguinte de Nietzsche e das páginas que na sua "autobiografia" dedicará ao nascimento do seu itinerário filosófico, perceber o estatuto das Unzeitgemässe Betrachtungen. Ao mesmo tempo que age utilizando as armas da crítica, Nietzsche cria uma imagem e uma figura de si como filósofo inatual. Um intelectual que fala para o seu próprio tempo, a partir de uma posição que é a antítese do tempo do qual fala e para o qual, simultaneamente, se dirige. Posição essa desconfortável, mergulhada

\footnotetext{
9 Eugen Fink, 1973, p. 10 (tradução do italiano de minha autoria). Uma posição semelhante encontramos também em Giorgio Colli, que, no começo do seu volume Dopo Nietzsche, escreve: "Quando se vê que, no frontispício de alguma edições quinhentistas de Niccolò Machiavelli, na Biblioteca Nacional de Florença, o nome do autor está apagado por mão desconhecida, por uma deleção de caneta, por desprezo do autor que tinha escrito sobre a 'fraqueza pela qual a presente religião tem conduzido o mundo', volta à cabeça Friedrich Nietzsche, e o que devem esperar da justiça dos posteros todos os que falam do seu presente com verdadeira dureza". Cf. Giorgio Colli, 1979, p. 17.
}

10 Como se lê no Prefácio ao Crepúscolo dos ídolos.

96 Cad. Nietzsche, Guarulhos/Porto Seguro, v.40, n.1, p. 92-123, janeiro/abril, 2019. 
Exercícios de inatualidade. As Considerações extemporâneas como...

na época e ao mesmo tempo subtraída da época. Símbolo da sua liberdade é o uso, como elemento de crítica, de formas culturais passadas ou de atitudes intelectuais diferentes, que podem assim ser introduzidas no tempo presente até descompô-lo.

Grande é, por outro lado, - escreve Nietzsche em Schopenhauer como educador - a esperança daqueles que não se sentem cidadãos deste tempo, porque se o fossem, contribuiriam para matar o seu tempo e desaparecer com o seu tempo - ao invés, querem antes despertar o tempo à vida para continuarem eles próprios a viver nesta vida (SE/Co. Ext. III, §1, KSA 1.339).

O filósofo luta, assim, contra o próprio tempo, e só “de maneira ilusória" esta luta é dirigida contra ele mesmo: nessa luta, o filósofo trava, na verdade, uma batalha "contra aquilo que lhe impede de ser grande, o que nele não significa outra coisa senão: ser livremente e inteiramente si mesmo" (SE/Co. Ext. III §3, KSA 1.362).

As quatro Intempestivas são inteiramente belicosas. Provam que eu não era nenhum "sonhador" e que me dá prazer puxar da espada - talvez provam que tenho a mão perigosamente leve. O primeiro ataque (1873) visava a formação intelectual alemã, para a qual, já então, eu olhava sobranceiramente e com impiedoso desdém. Sem sentido, sem substância, sem finalidade: não há equívoco mais pernicioso do que crer que o grande êxito militar dos Alemães prova alguma coisa a favor dessa cultura - ou que prova sequer a sua vitória sobre a França... A segunda Intempestiva (1874) traz a lume o que há de perigoso, corrosivo e tóxico para a vida no nosso tipo de empreendimento científico: a vida que fica doente com essa engrenagem e esse mecanismo desumanizados, com a "impessoalidade" do trabalhador, com a falsa economia da "divisão do trabalho". O fim, a cultura, perde-se - porque o meio, o moderno empreendimento da ciência, barbariza... Neste ensaio, o "sentido histórico", de que o nosso século se orgulha, foi pela primeira vez identificado como doença, como típico indício de degeneração. Na terceira e quarta Intempestivas, contrapõemse a isso, como indicações para um conceito mais elevado de "cultura", duas imagens do mais duro egoísmo e autodomínio, tipos intempestivos por excelência, cheios de soberano desprezo por tudo quanto à sua volta se chamasse "império", "cultura", "cristianismo", "Bismarck", "êxito" 
Ferraro, G.

- Schopenhauer e Wagner, ou, numa palavra, Nietzsche... (EH/EH, As exteporâneas, 1, KSA 6.316) ${ }^{11}$

Neste texto, que inicia a leitura que das Considerações Nietzsche dá em Ecce homo, temos de pôr em evidência pelo menos dois elementos. O primeiro é, claramente, o caráter polêmico que, uma vez mais, é afirmado relativamente às Considerações ("As quatro Intempestivas são inteiramente belicosas"), o segundo pertence à atitude filosófica que Nietzsche quis personificar por meio da recriação das figuras tipológicas, "intempestivas par excellence", com quem o próprio Nietzsche pode identificar-se.

Tentamos, portanto, observar como esses elementos se apresentam em algumas passagens. Já na primeira das Extemporâneas, dedicada a David Strauss, Nietzsche sublinha o principal objecto da sua crítica, ou seja, a "opinião pública", elevada a verdadeira soberana do discurso público e reguladora absoluta da moral social:

Na Alemanha parecia quase que a opinião pública proíba de falar das más e perigosas consequências da guerra, especialmente de uma guerra acabada vitoriosamente. Pelo contrário, são ouvidos com tão mais boa vontade os escritores que não reconhecem uma opinião mais importante que a pública e que, por causa disso, entram em competição para exaltar a guerra e seguir com júbilo os poderosos fenómenos da sua influência sobre moralidade, cultura e arte (DS/Co. Ext. I, 1, KSA 1.159).

Fazer essas afirmações imediatamente a seguir à vitória alemã sobre a França, com a subsequente constituição do Reich sob a direção prussiana, constituía, sem dúvida, um ataque feroz, não só contra a opinião pública, como também contra o "sentido comum", que queria antever naquela vitória não apenas a consequência direta

11 Todas as citações desta obra são da tradução publicada pela editora Relógio d'Água, 2000, conforme consta nas reefrências. (p. 179-180). Vale a pena lembrar, neste caso, as interpretações de Ecce homo de Branco e Paschoal, 2019: pp. 129-149 e pp. 151-157. Cf. também a interpretação de Roberto Calasso, 2005, pp. 153-202.

98 Cad. Nietzsche, Guarulhos/Porto Seguro, v.40, n.1, p. 92-123, janeiro/abril, 2019. 
Exercícios de inatualidade. As Considerações extemporâneas como...

do afirmar-se de uma potência política e econômica, mas a vitória de um horizonte simbólico e cultural sobre um outro. O "erro" que se espalha, portanto, na sociedade alemã é o de pensar que a vitória tinha sido a consequência lógica de uma superioridade alemã. Mas, aos olhos de Nietzsche, o que era mais perigoso não era tanto o erro em si mas a transformação ideológica que teria lugar na sociedade alemã, ocorrida a partir da interpretação, culturalmente declinada, da vitória militar: ao horizonte do "espírito alemão", que guiava a geração precedente, ir-se-ia sobrepor - como efetivamente estava a acontecer no círculo de amigos mais próximos de Nietzsche - o horizonte simbólico do império alemão:

Esta ilusão é sumamente ruinosa, talvez porque não ser uma ilusão existem de facto erros bastante saudáveis e benéficos - mas porque ela é capaz de transformar a nossa vitória numa completa derrota: na derrota, da extirpação do espírito alemão a favor do "império alemão" (DS/Co. Ext. I §1, KSA 1.159-160).

$\mathrm{Na}$ Alemanha, afirma Nietzsche, perdeu-se "o puro conceito de cultura". Se comparada à guerra entre Gregos e Macedônios, a guerra entre o Império Francês e a Prússia torna evidente como uma vitória militar não corresponde necessariamente a uma vitória cultural. Além disso, acrescenta Nietzsche, instrução e cultura caminham juntas: portanto, um conceito errado de cultura deve estar diretamente ligado a uma prática pedagógica falhada. A antiga paideia, a prática de formação dos antigos, é aqui retomada por Nietzsche ao observar na história contemporânea o que para ele se revela, em todo o caso, como um binômio indissolúvel "culturaformação". O falhado exercício de transformação de si, que qualquer formação implica, produz inevitavelmente um vazio cultural, ou, ainda melhor, uma falsificação.

Aos intelectuais cultos, que vivem na pretensão presunçosa de serem representantes de uma cultura superior, vencedora, Nietzsche dá o nome de "filisteus cultos". A sua característica principal, a 
Ferraro, G.

de acreditarem ser filhos e intérpretes de uma cultura, teria algo de supersticioso. Uma superstição derivada de maneira evidente sublinha Nietzsche - da "falta de qualquer conhecimento de si": o filisteu apresenta-se, antes de mais, como um não-filisteu e acha que a sua cultura possui quase um estigma de autenticidade. Uma falta de conhecimento de si que é afirmada também graças à presença de um cenário público e de um certo tipo de indústria cultural, justamente dominados por uma substancial falta de estilo e de cultura. Acontece, assim, que o filisteu da cultura vislumbra pontos de vista semelhantes e uniformes que o tranquilizam relativamente à sua missão e que legitimam a sua posição de funcionário e representante da cultura (Cf. DS/Co. Ext. I §2, KSA 1.165).

$\mathrm{Na}$ verdade, o que caracteriza a "cultura" do filisteu é precisamente a falta de cultura, ou seja, a falta da unidade de estilo que definiria para Nietzsche a cultura como tal. O horizonte do filisteísmo alemão impõe uma adoração acrítica dos clássicos, e contrapõe-se, neste sentido, ao livre experimentar que era característico da cultura alemã do início do século. É filho, portanto, do sentido comum da classe média intelectual alemã, aterrorizada pela vocação para a investigação e pela experimentação que tinham caracterizado as formas poéticas culturais do começo do século. A investigação livre assume, deste modo, traços suspeitos, antitéticos precisamente porque se contrapõem a uma cultura monolítica, idealizada como a efectiva representante da alta cultura como tal. Temos de sublinhar, nesse sentido, a relação íntima que Nietzsche individua entre um determinado carácter da sociedade e o tipo de intelectual que provém da classe média, com a suas típicas aspirações de reconhecimento social e, por isto mesmo, mais disponível a guardar o que lhe é dado do que a abrir novos horizontes. A "felicidade filisteia" do intelectual pode ser reconhecida, por Nietzsche, numa "certa complacência, uma complacência para o seu próprio canto, para a sua própria tranquilidade e até para a sua própria escassez" (DS/Co. Ext. I §2, KSA 1.168-169).

$100 \mid$ Cad. Nietzsche, Guarulhos/Porto Seguro, v.40, n.1, p. 92-123, janeiro/abril, 2019. 
Exercícios de inatualidade. As Considerações extemporâneas como...

O filisteísmo aparece como uma cultura do "conforto" e, nesse sentido, o idealismo alemão constitui, para Nietzsche, a forma filosófica por excelência desta cultura. David Strauss pode, assim, figurar como o exemplo do filisteu: ao contrapor-se a Schopenhauer, Strauss julga o pensamento do grande filósofo - e também este juízo pode ser observado como um sintoma particularmente significativo - como "muitas vezes nocivo e estéril" (DS/Co. Ext. I §2, KSA 1.171). Um dos aspectos decisivos do filisteísmo é também uma certa forma de cinismo: o filisteu olha para a beleza como para um elemento ultrapassado da cultura presente, e isto acontece por causa da sua própria fraqueza. Mas uma fraqueza que se torna poder: o que fala no filisteu é sobretudo um homem de poder. Com a sua fé irredutível e o seu fanatismo, o filisteu pode ser visto como um "fundador de religiões", isto é, um indivíduo capaz de encarnar a mesma potência dos antigos profetas, virando-a, de qualquer forma, noutras direcções. Uma forma de potência que a Nietzsche se afigura como parasitária, incapaz de se expressar autonomamente e enfrentar "corpos" superiores aos próprios:

Um cadáver é um bom pensamento para o verme, e o verme um pensamento terrível para todos os viventes. Os vermes sonham o seu reino dos céus num corpo gordo, os professores de filosofia sonham-no mexendo nas vísceras schopenhauerianas; e enquanto houver roedores, haverá também um céu de roedores. E isso responde à nossa primeira pergunta: como imagina o novo crente o seu céu? O filisteu straussiano habita nas obras dos nossos grandes poetas e músicos como um ninho de vermes que vivem destruindo, que admiram devorando, que adoram digerindo (DS/Co. Ext. I §6, KSA 1.188).

Os grandes do passado são, para o filisteu, retomados no presente com a condição de serem neutralizados na sua força, na sua efetiva capacidade de deslocar o presente. Assim, também a ação do filisteu é uma ação mimética verbal, que não aspira a modificar as relações de força: "Ele não chega a uma ação agressiva, se não apenas a palavras agressivas" (DS/Co. Ext. I, 7, KSA 1.194). Só de 
Ferraro, G.

uma "necessidade de descanso" pode ser testemunha Strauss, para Nietzsche: não seria outra coisa o livro senão um "livro de religião para os eruditos", na verdade, um espelho da vida que os próprios eruditos vivem. Assim, também as instituições, os círculos literários, bem como as universidades onde agem os filisteus, se tornam para Nietzsche lugares cansados, onde alguns discursos se relegitimam, sem nunca permitir a insurgência de um elemento crítico devido à competição autorreferencial onde se simula uma cultura, sem que se seja efetivamente capazes de a produzir. A este estatus quo, Nietzsche contrapõe uma "profissão de fé", contrariamente fundada numa ética da coragem e da verdade e numa observação sem concessões para o mundo atual, precisamente através da lente das formas "inatuais" / "extemporâneas" da cultura:

E com isto fiz a minha confissão. É a confissão de um indivíduo; e o que poderia fazer um indivíduo contra o mundo inteiro, para que a sua a voz fosse ouvida por todo o lado? O seu juízo contaria, porém, para decorarvos com uma genuína e preciosa pluma de avestruz, só uma "verdade tão subjetiva, como desprovida de toda a força demonstrativa objetiva" - não é verdade, meus lindos? Tranquilizem-se, portanto. Por agora, pelo menos, será preciso contentar-vos com o vosso "tão - como desprovida". Por agora! Até quando será considerado inatual o que atual sempre foi e que hoje, mais do que nunca, é atual e é preciso - dizer a verdade. - (DS/Co. Ext. I §12, KSA 1.241-242).

Este "dizer a verdade" parece, portanto, reassumir o sentido da guerra que Nietzsche empreende contra o seu próprio tempo e contra a sombra que a cultura contemporânea lança sobre ele e sobre a sua própria ação. Uma ação precisamente antitética à do filisteísmo cultural dominante, representado por Strauss, e que, contrariamente, encontra na "profissão de fé" do filósofo a tarefa íngreme, a necessidade inatual posta no centro das Extemporâneas. Justamente do outro lado do fio que se abre através da polêmica com Strauss - figura do filisteu da cultura e o mais autêntico herdeiro de 
Exercícios de inatualidade. As Considerações extemporâneas como...

todas as fraquezas culturais, contra as quais estão forçados a exercerse todos os autênticos pensadores - encontramos a Extemporânea sobre Schopenhauer.

Filósofo-guia para Nietzsche, e filósofo ao qual, pelo contrário, cordialmente se opõem os filisteus, Schopenhauer deve ser visto aqui, antes de mais, como o nome que representa toda uma peculiar modalidade de pensamento, como forma em que se concretiza uma alteridade radical ao tempo presente. O que significa, para o Nietzsche das Extemporâneas, o nome de "Schopenhauer"? E o que significa para si, precisamente no momento em que escolhe enfrentar a atitude filosófica do seu grande mestre, ser "inatual" - pensar de maneira inatual, pôr questões inatuais - relativamente ao próprio tempo? Isto é, o que implica um modelo de pensamento que temos de perceber como um "cavar dentro de si", um agir que nos permite atingir a esfera espiritual dos nossos educadores, daqueles que são capazes de nos mostrar o caminho que conduz ao nosso bem, à nossa liberdade, à "matéria fundamental" do nosso ser? Um ser, diga-se de passagem, que havemos de conceber como "algo de absolutamente ineducável e imaleável". Na III Extemporânea, Nietzsche nunca tem como objectivo descrever a cosmologia schopenhaueriana, definir os percursos e as fontes históricas, trata-se aqui de projetar uma luz sobre os caracteres que fazem do pensamento de Schopenhauer uma modalidade de pensamento inatual/intempestivo/extemporâneo e, contudo, mais do que nunca urgente na atualidade, precisamente onde ela encarna a urgência da verdade, antitética à época presente. $\mathrm{O}$ que fica de Schopenhauer é, por assim dizer, o olhar sobre o abismo que uma atitude semelhante à sua torna possível.

Nesse sentido, o conjunto das Considerações - é o próprio Nietzsche a sugerir-nos a possibilidade de as considerar como um corpus, fornecido como tal, de uma sua identidade - parecem indicar ao leitor um caminho que introduz o próprio pensamento de Nietzsche. Isto é, uma possibilidade de introdução não simplesmente a conteúdos 
Ferraro, G.

formalizados ou a uma lógica válida para todo o pensamento de Nietzsche, como às mesmas formas através das quais Nietzsche pede a si próprio e ao leitor de pensar. Encontramos, pela primeira vez, aqui desenvolvidos os pressupostos de método, que não só Nietzsche nunca irá abandonar mas que encontraremos novamente no final do seu itinerário filosófico: pressupostos que ligam o pensamento e um determinado modelo de pensar, de maneira polêmica, a uma ação. Para Nietzsche, o pensar aparece aqui ligado diretamente a um agir concreto, a uma intervenção nas formas da cultura, compreendida como coágulo de praxis, como conjunto de atitudes e de referências de valor que só na praxis, e na história das praxis, encontram a sua legitimação, as suas fortuitas ligações, as suas fraturas. Em suma, as suas possibilidades. ${ }^{12}$

Em particular, e de maneira antitética relativamente à que se pode observar na Extemporânea sobre Strauss, na Extemporânea sobre Schopenhauer como educador vemos em ação um pensamento que volta a pôr em jogo as formas do exemplo e da regra filosófica, que para Nietzsche é aqui também regra de vida, semelhante à dos antigos modelos performativos. $\mathrm{O}$ desenvolvimento de um horizonte de formação de uma nova cultura, ou de enxertos e elementos "inatuais" capazes de subverter a ordem do discurso e dos valores da cultura presente. É nesse horizonte que a filosofia pode desenvolver a sua própria tarefa e é só neste contexto que podemos individuar o sentido desta prática também na modernidade. Uma prática que quebra os ritmos do "conforto" intelectual para introduzir um sinal de diferença.

12 Indicativas, desta abordagem à reflexão da parte de Nietzsche, são as palavras que dirige ao seu amigo Carl von Gersdorff, quase duas semanas após ter entregado ao prelo, no Setembro do 1874, a última parte do manuscrito da III Extemporânea: "Foi uma altura difícil, meu querido amigo, esta última parte do nosso semestre de verão, e eu respiro aliviado agora que passou. Na verdade, além dos trabalhos de costume, tive que elaborar por completo uma parte bastante longa da minha número três, o inevitável esgotamento e perturbação da alma, devidos a este meditar e cavar no fundo, quase me atropelaram, e também ainda não me restabeleci da febre puerperal. Acima de tudo, porém, dei à luz algo, na verdade, muito bom, penso com satisfação à alegria que irás experimentar quando o leres": SB/ KSA 4.257 (Mai 1872 - Dezember 1874), An Carl von Gersdorff, <Basilea, 24 settembre 1874>.

104| Cad. Nietzsche, Guarulhos/Porto Seguro, v.40, n.1, p. 92-123, janeiro/abril, 2019. 
Exercícios de inatualidade. As Considerações extemporâneas como...

As perguntas postas na fonte da III Extemporânea subvertem aquelas que Nietzsche lançava contra Strauss: se naquelas o problema era o de perceber como age a filosofia filisteia, aqui trata-se de perceber como exercitar uma filosofia, como ser filósofo com o fim de garantir que este agir está, efetivamente, à altura da tarefa que ele requer. E são duas as maneiras que Nietzsche considera como as premissas desta atividade: por um lado, a "libertação, remoção de todo o mato, dos detritos, dos vermes, que querem atacar a semente delicada das plantas, irradiação de luz e calor, imitação e adoração da natureza" (SE/Co. Ext. III §1, KSA 1.341). E, em segundo lugar - e, sublinha Nietzsche, temos aqui de perceber a atividade formativa como uma atividade por meio da qual nos (re)encontramos "para acordar do atordoamento no qual habitualmente nos vamos agitando" (SE/Co. Ext. III §1, KSA 1.341) - um lembrar-se dos nossos "educadores e formadores", não só nas noções, como também na sua forma de vida. Pensar a filosofia como vida, como pedra de toque de uma vocação. É aqui que esta modalidade do pensamento de Nietzsche pode ser observada e analisada à luz daquela tradição dos "exercícios espirituais" que Pierre Hadot sublinhava como modalidade específica através da qual se atuava a prática filosófica na antiguidade e em alguns pensadores modernos, como também à luz daquela particular tradição filosófica da qual Michel Foucault faz uma genealogia, em várias intervenções dos anos 80 e mais em geral nos seus cursos ao Collège de France dos anos 80, particularmente nos seus dois últimos $O$ governo de si e dos outros e a Coragem da verdade: a parrésia. Uma genealogia, a foucauldiana, da concatenação que - a partir do seu surgimento na época grega, e depois ao longo de linhas específicas que tocam, por exemplo, a tradição epicureia, estoica e a cínica liga a atividade filosófica às práticas concretas da vida, criando novos modelos de pesquisa da verdade e de expressão do pensamento em 
Ferraro, G.

termos performativos, precisamente através da intersecção, ética e politica, com a vida. ${ }^{13}$

Nietzsche surge, de resto, e precisamente a este propósito, na genealogia filosófica de Foucault, como o próprio Foucault afirma. Num texto publicado em 1984, Foucault expressa a sua conceição de trabalho crítico: um trabalho crítico diretamente ligado à herança do grande projecto de transformação do iluminismo, nos termos de um trabalho filosófico sobre a própria subjetividade: "Não sei se é preciso dizer hoje que o trabalho crítico implica ainda a fé nas Luzes; ele necessita, creio, sempre do trabalho sobre os nossos próprios limites, ou seja, de um labor paciente que dê forma à impaciência da liberdade". ${ }^{14}$ Para perceber o alcance desta afirmação, é preciso, portanto, retomar a noção de "ontologia da atualidade", uma noção que o próprio Foucault coloca ao lado duma outra, "ontologia crítica de nós mesmos". Noções, estas, que encontramos em dois textos, elaborados em 1983 e em 1984, em que Foucault comenta o texto de Kant sobre o Iluminismo, Was ist die Aufklärung? e o texto de Kant sobre a revolução, Idee zu einer allgemeinen Geschichte in weltbürgerliche Absicht. ${ }^{15}$ Algo em particular, não secundário, a destacar, é que Foucault desenha nesses textos uma genealogia filosófica sua. Uma genealogia na qual encontramos autores que são agrupados devido a uma precisa relação entre o seu trabalho filosófico e o seu presente histórico, e, antes de mais, por uma pergunta-chave: o que é a atualidade? Uma questão a partir da qual Kant teria dado

13 Faço aqui referência, no caso de Hadot, aos dois textos La philosophie comme manière de vivre. Paris: Albin Michel, 2001 e Exercises spirituels et philosophie antique. Paris, Albin Michel, 2002. No caso de Foucault, faço referência a vários textos presentes no volume II dos Dits ét écrits (Dits et écrits II. 1976-1988. Paris: Gallimard, 2001) e aos dois cursos Le gouvernement de soi et des autres (Paris: Gallimard, 2008) e Le courage de la vérité (Paris: Gallimard, 2009).

14 Michel Foucault, 2001, p. 1397 (as traduções de Foucault são de minha autoria).

15 Cf. Michel Foucault, 2001, pp. 1381-1397 e pp. 1498-1507.

$106 \mid$ Cad. Nietzsche, Guarulhos/Porto Seguro, v.40, n.1, p. 92-123, janeiro/abril, 2019. 
Exercícios de inatualidade. As Considerações extemporâneas como...

vida, esclarece Foucault, a uma grande tradição crítica que atravessará os séculos seguintes. Nas palavras de Foucault:

Existe, porém, na filosofia moderna e contemporânea, um outro tipo de questão, uma outra maneira de interrogação crítica: é a que se vê nascer precisamente na questão do Aufklärung ou no texto sobre a revolução; esta outra crítica coloca a questão: "O que é a nossa atualidade? Qual é o campo atual das experiências possíveis?". Não se trata aqui de uma analítica da verdade, tratar-se-á daquilo que se poderia nomear como uma ontologia do presente, uma ontologia de nós mesmos, e parece-me que a escolha filosófica com que acabamos por confrontar-nos atualmente é esta: pode-se optar por uma filosofia crítica que se apresentará como uma filosofia analítica da verdade em geral, assim como se pode optar por um pensamento crítico que irá assumir a forma de uma ontologia de nós mesmos, de uma ontologia da atualidade; é essa forma de filosofia que, desde Hegel até a escola de Francoforte, passando por Nietzsche e Max Weber, fundou uma forma de reflexão na qual tentei trabalhar. ${ }^{16}$

Para Foucault, toda a história da filosofia subsequente ao período iluminista pode ser pensada como uma tentativa de responder à pergunta posta pelo Aufklärung. De sublinhar que esta pergunta constitui uma nova declinação da interrogação filosófica sobre o presente. Em Kant não se trataria de definir a especificidade do presente a partir de uma totalidade ou como a premissa de um acontecimento futuro. Tratar-se-ia, pelo contrário, na interpretação de Foucault, de individuar a "diferença" essencial, o que torna o presente diferente do mundo de ontem, por sua vez, único e não replicável. Esta "diferença" do seu tempo é, portanto, representada em Kant pelo acontecimento específico e irreversível designado como "saída do estado de minoria", ou seja, como um processo através do qual os sujeitos - e Foucault faz notar haver nisso uma correspondência direta na elaboração tripartida das Críticas - se libertam de uma

16 Michel Foucault, 2001, pp. 1506-1507.

Cad. Nietzsche, Guarulhos/Porto Seguro, v.40, n.1, p. 92-123, janeiro/abril, 2019. 
Ferraro, G.

condição de sujeição perante a direção de consciência de um livro, de um diretor, ou de um médico.

Foucault assinala, por outro lado, como a condição fundamental da saída do estado de minoria, para Kant, a tomada de consciência pelo próprio sujeito. De maneira diferente, o problema de uma libertação do estado de minoria aparenta ser para Kant, aos olhos de Foucault, o de uma mudança de forma do próprio sujeito. Só indo além da forma na qual a precedente condição o fecha, o sujeito pode, efetivamente, migrar para uma forma diferente: trata-se, portanto, quase de "vestir" uma tarefa que é antes de mais uma tarefa crítica relativamente a si próprio. $\mathrm{O}$ traço que caracteriza o pensamento moderno, no sulco do qual se inscreveria, portanto, a ligação entre o pensamento genealógico de Nietzsche e o projecto de Foucault, definir-se-á como a reflexão entorno do estatuto duma atitude. Nas palavras de Foucault:

Referindo-me ao texto de Kant, pergunto-me se não se poderá pensar a modernidade como uma atitude, em vez de um período da história. Por atitude entendo uma maneira de relação com a atualidade, uma escolha voluntária que é feita por alguns, enfim, uma maneira de pensar e de sentir, também uma maneira de agir e de se conduzir que, ao mesmo tempo, sublinha uma pertença e se apresenta como uma tarefa. Um pouco, sem dúvida, como aquilo que os Gregos chamavam de ethos. ${ }^{17}$

Se a atitude da modernidade é caracterizada por uma "crítica permanente do nosso ser histórico"18, trata-se, portanto, de interrogar sobre a maneira através da qual "a análise de nós mesmos" pode orientar-se para com a "constituição de nós próprios como sujeitos autônomos"19, numa fidelidade fundamental ao projecto

17 Michel Foucault, 2001, p. 1387.

18 Michel Foucault, 2001 p. 1390.

19 Michel Foucault, 2001, p. 1391.

108 Cad. Nietzsche, Guarulhos/Porto Seguro, v.40, n.1, p. 92-123, janeiro/abril, 2019. 
Exercícios de inatualidade. As Considerações extemporâneas como...

de esclarecimento iluminista, onde este pode ser avaliado como projecto de libertação de uma condição de subjugação.

O ethos filosófico que Foucault individua, e que deve ser a base de uma investigação crítica, caracteriza-se como um "teste históricoprático dos limites que podemos ultrapassar e, nessa medida, como trabalho de nós mesmos enquanto seres livres". ${ }^{20}$ É, então, na sua atitude "experimental" 21 que se jogaria para Foucault o próprio problema da liberdade do sujeito moderno pós-iluminista, num confronto crítico entre a forma de si próprio e a forma do tempo em que se vive. É nesta relação, nunca estabilizada, que teria lugar a parte maior do ethos moderno: o sujeito da modernidade é aquele que, tendo individuado esta relação como instrumento de constituição da subjugação individual e coletiva, pode permitir-se o gosto da autonomia. Nesse sentido, a atitude crítica é uma atitude que, além de ser naturalmente ética, se define também como ontológica. É a este propósito que Foucault fala de uma "ontologia crítica de nós mesmos".

A ontologia crítica de nós mesmos deve ser considerada não apenas como uma teoria, uma doutrina, e nem sequer como um corpo permanente de saber que se acumula; é preciso concebê-la como uma atitude, um ethos, uma vida filosófica, em que a crítica daquilo que nós somos é, ao mesmo tempo, análise histórica dos limites que nos são dados e teste da possível superação dos mesmos. ${ }^{22}$

A herança mais consistente do Iluminismo, herança essa recolhida e repensada por Kant no seu texto, consiste, aos olhos de Foucault, num trabalho crítico sobre os limites do "hoje", como "diferença na história e como motivo para uma tarefa filosófica". ${ }^{23}$

20 Michel Foucault, 2001, p. 1394.

21 Michel Foucault, 2001, p. 1393.

22 Michel Foucault, 2001, p. 1396.

23 Michel Foucault, 2001, p. 1387.

Cad. Nietzsche, Guarulhos/Porto Seguro, v.40, n.1, p. 92-123, janeiro/abril, 2019. 
Ferraro, G.

É esta a perspectiva através da qual Foucault interroga também as tradições que intersectam a parresia, ou seja, as formas de exercício da verdade que põem em questão a própria vida. A vida filosófica aparece nessa perspectiva como a prática que os antigos cínicos, ou os mártires cristãos, exprimiam, precisamente através da representação da verdade, chegando mesmo à exposição do seu próprio corpo; exposição à morte, por vezes, mas sempre exposição ao limite que a opinião pública impunha ao exercício da verdade. Da mesma forma, Foucault reconhece também nas tradições filosóficas modernas um modelo performativo em que o exercício do pensamento não aparece nunca destacado da presença de uma atitude crítica para com o tempo presente, atitude crítica que impõe ao intelectual a necessidade de interrogar a sua posição no mundo, através de um confronto com o presente, e de verificar as formas da sua verdade através de uma análise impiedosa das condições com que a verdade se apresenta e se encarna nos sujeitos. Foucault define esta linha da filosofia moderna como "ontologia", consequentemente, como uma verdadeira investigação sobre o ser: "ontologia do presente", "ontologia da atualidade", "ontologia crítica de nós mesmos" são as expressões que o autor alterna nesse período, expressões em que o inquérito ontológico aparece ligado, por um fio duplo, a uma pesquisa sobre as formas históricas através das quais o ser, e a sua verdade, se dão no presente. É à luz deste inquérito, que coloca em causa o filósofo assim como o seu público, que a questão ontológica se constituiria na modernidade, antes de mais, como ontologia crítica das atitudes. E não é difícil avistar, então, nesse horizonte, que Foucault deduz da interrogação-chave que inaugura a modernidade pós-iluminista, a questão, ou melhor, a atitude que permeia as Considerações de Nietzsche: a de uma "contra-modernidade".24

24. Michel Foucault, 2001, p. 1387.

$110 \mid$ Cad. Nietzsche, Guarulhos/Porto Seguro, v.40, n.1, p. 92-123, janeiro/abril, 2019. 
Exercícios de inatualidade. As Considerações extemporâneas como...

Nessa perspectiva, o projeto das Considerações de Nietzsche parece querer intervir no presente, construir, por sua vez, uma forma de ontologia crítica das atitudes da modernidade - linguísticas, artísticas, filosóficas, psicológicas (e sabemos como este será um dos fils rouges mais firmes no pensamento nietzschiano). Sob o nome de "unzeitgemässigkeit", "extemporaneidade", "intempestividade", ou "inatualidade", parece vir a lume a mesma exigência da uma interrogação crítica da "atualidade", sobre a qual Foucault escreve. E, nesta interrogação crítica, surge uma tarefa filosófica que tem como alvo a construção de uma diferença relativamente ao tempo atual, isto é, de uma "contra-modernidade". Lembramos como Nietzsche abre a quarta Extemporânea, Richard Wagner em Bayreuth, expressando, quase, uma "ontologia do acontecimento":

Para que um acontecimento tenha grandeza, é preciso que duas coisas se reúnam: o grande ânimo daqueles que o cumprem e o grande ânimo daqueles que tomam parte nele. [...] Assim, quem vê aproximar-se um acontecimento, perguntar-se preocupado se os que tomam parte nele serão dignos dele. É este corresponder-se de ação e receptividade que se deve ter em conta e é isto que sempre se aponta, quando se age, nas coisas menores assim como nas maiores...(WB/Co. Ext. IV §1, KSA 1.431).

Ao mesmo tempo, raspando o que está na superfície das atitudes, paras descubrir o que está no fundo das formas culturais que se coagulam em instituições, ou das instituições que se coagulam em atitudes, esses textos retomam uma tradição da filosofia como "maneira de viver", e não como simples exercício teórico. Um exercício "prático" que, no seu constante diálogo com o presente e com o núcleo de filisteísmo que ele apresenta, abre à possibilidade da "vida outra" que Foucault individua como trato, quer da tradição da parrésia, quer da interrogação moderna sobre a atualidade. No seu apelo polêmico a uma conversão filosófica, Nietzsche surge, portanto, nas Extemporâneas, dentro do horizonte aberto por Foucault, 
Ferraro, G.

como autor moderno e ao mesmo tempo "contra-moderno". Escreve Nietzsche na III Extemporânea:

Porém, mesmo que o futuro não nos deixe esperar nada, a nossa singular existência precisamente na hora atual - o fato inexplicável que vivemos hoje e, contudo, tivemos o tempo infinito para nascer, que não possuímos se não um curtíssimo hoje e nele temos de mostrar por que e para que fim nascemos - encoraja-nos da maneira mais enérgica a viver segundo uma medida e uma lei nossa. Sobre a nossa existência temos de responder nós mesmos, por conseguinte, queremos agir como os seus verdadeiros timoneiros e não permitir que seja semelhante a uma casualidade desprovida de pensamento. Ela requer uma certa temeridade e um certo azar uma vez que, no melhor dos casos, perder-se-á (SE/Co. Ext. III §1, KSA 1.339).

Portanto, a tarefa da filosofia não é simplesmente indicar ao indivíduo uma lei da existência, mas também ensinar a procurar uma lei sua, uma medida sua. Trata-se de individuar o sentido da existência, não num abstrato mundo ideal, mas no até demasiado humano solo das possibilidades que para nós têm validade e que tornam este "nós" não fruto de uma casualidade mas de uma capacidade de dar forma. Dar forma à existência, definir a sua posição no presente e a partir do presente parece ser para Nietzsche o que está na própria base da vocação filosófica (Cf. SE/Co. Ext. III §1, KSA 1.340). Nesse difícil caminho para evitar os véus que nos separam de nós mesmos, "Não questiones" aonde conduz o caminho, escreve Nietzsche. "Melhor, segue-o" (Cf. SE/Co. Ext. III §1, KSA 1.340). E já com estas premissas vemos como a forma filosófica das Considerações surge como uma forma "prática". Particularmente em Schopenhauer como educador, o jovem Nietzsche põe em evidência a preguiça e cobardia que caracterizariam os homens na sua generalidade (Cf. SE/Co. Ext. III $§ 1$, KSA 1.337). Uma preguiça que os conduz a adaptar-se aos hábitos da maioria e a ter escondida, como uma má consciência, a improvável fatalidade que produziu a irrepetibilidade e a unicidade da sua existência. "Pseudohomens [Scheinmenschen] com uma opinião 
Exercícios de inatualidade. As Considerações extemporâneas como...

pública" (Cf. SE/Co. Ext. III §1, KSA 1.338) é o caráter próprio da época atual de Nietzsche, o que a tornaria insignificante para as gerações seguintes. $\mathrm{O}$ compromisso com o presente é, nesse sentido, o que afasta o homem de si próprio: do abismo da sua existência, do seu pensamento e do seu desejo.

Mas como podemos voltar a encontrarmo-nos a nós mesmos? Como pode o homem conhecer-se? Ele é algo obscuro e escondido; e se a lebre tem sete peles, o homem pode tirar dele estas setenta vezes sete e não poderá dizer: "eis, isto é o que tu és realmente, esta já não é mais cortiça". Além disso, é um início doloroso, arriscado, cavar por si mesmo desta forma e descer com violência pelo caminho mais curto no poço do próprio ser. Facilmente pode magoar-se ao fazer isto, de tal maneira que nenhum médico conseguirá curá-lo. [...] Mas há um meio para colocar a questão mais importante: encara a jovem alma, do teu passado, e pergunta: o que até agora amaste na verdade, o que te atraiu, o que te dominou e ao mesmo tempo te tornou feliz? Põe em frente de ti esses objectos queridos e talvez eles te mostrem, pela sua essência e a sua sucessão, uma lei, a lei fundamental do teu eu próprio verdadeiro (SE/Co. Ext. III §1, KSA 1.340).

Seguir o próprio caminho aplica-se também ao trabalho que a alma tem que desempenhar consigo própria. $\mathrm{O}$ trabalho de colocar em frente de si os objetos que encarnam ou que encarnaram a felicidade significa produzir o conhecimento que nos leva a seguir o nosso caminho. $\mathrm{O}$ único caminho que se destaca em frente de nós, o único que podemos atravessar. Trata-se de um radical trabalho de crítica que a jovem alma tem de desempenhar sobre si mesma. O papel da "formação" e, portanto, do trabalho dos educadores, seria o de dar acesso a esta "matéria fundamental do teu ser" (SE/Co. Ext. III §1, KSA 1.341). Precisamente por causa disto os educadores não podem ser outra coisa senão libertadores. $E$ é por esta mesma razão que "reencontrar-se" implica, portanto, também um exercício de lembrança dos educadores, ou seja, daqueles que nos abriram, afirma Nietzsche, o lugar que permitiu à nossa alma perceber o seu próprio caminho. É nesse sentido que o trabalho 
Ferraro, G.

da educação não é um trabalho feito através de justaposições, mas sim um trabalho por subtração, um exercício feito através de exempla. ${ }^{25}$ A "corajosa visibilidade" da vida filosófica é, portanto, o que faz falta aos modernos e que, pelo contrário, caracteriza os antigos: trata-se da "visibilidade" da vida filosófica que Foucault observará nas formas parresiásticas do cinismo antigo, assim como nos aspectos aparentemente extra-filósoficos da vida dos modernos. Exatamente nos que Nietzsche sublinha: "o aspecto, a atitude, o vestido, a comida, os hábitos". ${ }^{26}$

O próprio sentido da filosofia aparece nessas linhas de Nietzsche, aqui ainda em termos programáticos, como um exercício espiritual dirigido à vida e à transformação da vida. A compreensão metafísica do mundo, e uma compreensão isenta de todas formas de compromisso com o medo e com o poder, é só a premissa para chegar à definição da regra de vida através da qual escolher e viver uma vida individual. Por outro lado, o aprofundamento da vida individual consente aceder à coragem necessária para olhar o abismo do mundo. Se, portanto, o exemplo que nos é dado pela "vida filosófica" de Kant não pode ter outra saída a não ser aquela de gerar "antes de mais, professores de universidade e uma filosofia de professores" (SE/Co. Ext. III §3, KSA 1.351), pelo contrário, figuras como a de Montaigne ou a de Schopenhauer, este último relativamente afastado das instituições da universidade e do Estado, podem produzir uma

25 "Mas o exemplo deve ser dado através da vida visível, e não simplesmente através de livros, como ensinavam os filósofos da Grécia: pelo aspecto, a atitude, a roupa, a comida, pelos hábitos, ainda mais que pela conversa ou até pela escrita": SE/Co. Ext. III §3, KSA 1.350.

26 Foucault esclarece como a expressão martyron tês alêtheias, testemunha da verdade, mesmo que tardia, pode caracterizar as formas filosóficas do cinismo antigo, arquétipo das tradições nas quais a relação com a verdade é atravessada pela relação com o corpo: "O próprio corpo da verdade é tornado visível, e risível, num certo estilo de vida. A vida como presença imediata, evidente e selvagem da verdade, é isto que se manifesta no cinismo": Michel Foucault, 2009, p. 160. A propósito dos cínicos, em Nietzsche, $c f$. a passagem da Extemporânea Da utilidade e desvantagem da história para a vida HL/Co. Ext. II §1, KSA 1.249.

$114 \mid$ Cad. Nietzsche, Guarulhos/Porto Seguro, v.40, n.1, p. 92-123, janeiro/abril, 2019. 
Exercícios de inatualidade. As Considerações extemporâneas como...

forma de verdade radicalmente alternativa à forma de verdade que caracteriza a época presente. ${ }^{27}$

Desaprender esta forma de verdade, seguindo o exemplo schopenhauriano, constitui, portanto, o núcleo daquilo que torna inatual a mesma filosofia de Schopenhauer: compreende-se como a educação do filósofo, no seu complexo, tem que ser orientada para a inatualidade. Ou seja, interpretando Nietzsche pelas categorias de Foucault, diríamos que há uma critica, que é, por si, inatual, extemporânea. Uma inatualidade relativamente às formas atuais do poder e do pensamento, que se constituem e se legitimam dentro de formas de vida. Inatualidade relativamente às mesmas instituições que cristalizam, ou pretendem cristalizar, as formas da jovem alma. Tornando-a frouxa, insincera. E é precisamente aqui que se esconde o núcleo daquilo que Nietzsche pensa como "intempestivo": "simples e sincero, no pensamento e na vida, portanto intempestivo no sentido mais profundo da palavra" (SE/Co. Ext. III §2, KSA 1.346). Se a modernidade é caracterizada por uma profunda insinceridade que define a atitude dos seus sujeitos (Cf. SE/Co. Ext. III §2, KSA 1.346), a vida filosófica de Schopenhauer é, portanto, produto de uma profunda fadiga de contraposição ao mundo presente. Schopenhauer vive no risco constante da solidão, risco que todos os "homens insólitos" têm de atravessar, para poder aderir ao seu caminho. Assim, o exemplum vitae "Schopenhauer" aparece aqui nas roupas do guia do mito platónico, que conduz os humanos a observar a luz fora da caverna. Nas palavras de Nietzsche, como "o guia que conduz fora da caverna da apatia cética, da renúncia crítica, no alto, para o cimo da contemplação trágica - o céu noturno com as suas estrelas infinitamente acima de nós, - e que o levou a ele mesmo, primeiramente, por este caminho" (SE/Co. Ext. III §3, KSA

27 Cf. HL/Co. Ext. II §1, KSA 1.249. A propósito da figura de Montaigne, que Nietzsche considera até "mais acima" de Schopenhauer, $c f$. SE/Co. Ext. III §2, KSA 1.348: "Schopenhauer tem em comum com Montaigne ainda uma segunda qualidade, além da honestidade: uma verdadeira serenidade que anima [erheiternde Heiterkeit]. Aliis laetus, sibi sapiens". 
Ferraro, G.

1.356). A exigência de todas as grandes filosofias é reconduzível, para Nietzsche, à necessidade de perceber, a partir do quadro que inclui "a vida toda", ao mesmo tempo que, pelo contrário, é possível atingir a vida universal, os seus "hieroglíficos", apenas através de uma leitura atenta, sincera, da própria vida (Cf. SE/Co. Ext. III §3, KSA 1.357): "Cada um leva consigo, como cerne do seu ser, uma unicidade produtiva; e, se se tornar consciente dessa unicidade, à sua volta espalha-se um brilho incomum, o brilho daquilo que é insólito" (SE/Co. Ext. III §3, KSA 1.359). Contudo, o filósofo "inatual” deve lutar contra o "endurecimento moral ou intelectual" (SE/Co. Ext. III §3, KSA 1.360) que o pode afetar. O filósofo torna-se, assim, um espelho do seu tempo. "Enteado" da sua própria época, ele combate-a, e combate, nesse sentido, contra si mesmo. Mas só ilusoriamente esta luta é uma luta autodestrutiva: ele combate o que o impede, nele mesmo, "ser grande" (SE/Co. Ext. III §3, KSA 1.362).

Nesse sentido, o trabalho filosófico é pensado nas Considerações, antes de mais, como um trabalho do filósofo sobre si próprio, na maneira de um exercício semelhante aos dos antigos: ontológico e crítico, no sentido em que abre o ser a uma nova modalidade de se atuar. Desde logo, vê-se como se trata de uma herança que a modernidade recebe da antiguidade, e, nas suas formas próprias, a desenvolve: o exercício filosófico dos antigos, o trabalho paciente do filósofo sobre si próprio, torna-se necessariamente um trabalho mediado pela sua própria época. É afastando-se das características da sua época, tornando-se, portanto, "inatual", que ele pode atingir a verdade do seu ser. ${ }^{28}$

Ao olhar e julgar as épocas segundo os valores que não são os valores do presente, o filósofo é forçado quase que a "ultrapassar o

28 Como já esclarecido, utilizo a noção de "exercício filosófico" no sentido de Pierre Hadot, que cita o exemplo da III Extemporânea para destacar o uso desta praxis filosófica na modernidade. Cf. Pierre Hadot, 2002, pp. 116-117; pp. 136-137

116 | Cad. Nietzsche, Guarulhos/Porto Seguro, v.40, n.1, p. 92-123, janeiro/abril, 2019. 
Exercícios de inatualidade. As Considerações extemporâneas como...

presente"29 dentro de si, assim como é forçado a ultrapassar o presente na sua própria época, desenvolvendo uma atitude polêmica que lhe permite promover os elementos de ruptura radical através dos quais dá vida, isto é, a uma geração de seres capazes de enfrentar a verdade.

A sua inimizade é dirigida, essencialmente, contra aquilo que fica com certeza nele próprio, ou seja, contra a impura confusão e coexistência daquilo que é inconfundível e eternamente inconciliável, contra a falsa junção entre o actual e ou seu inatual (SE/Co. Ext. III §3, KSA 1.362).

Formar-se no seio da liberdade significa, nesse sentido, formarse contra o próprio tempo: levar a crítica a consequências extremas que implicam a solidão do sujeito inatual, sem ter medo de que, por causa disso e através da crítica do seu tempo, a própria forma de subjetividade e as tranquilizantes premissas com as quais vivemos no mundo entrem em crise. A inimizade do filosofo inatual é, portanto, dirigida contra a projecção do seu tempo dentro de si, contra a forma que o tempo pretende dar à sua própria alma. A ontologia crítica dos modernos, e em particular a ontologia da "inatualidade" de Nietzsche, torna-se aqui, necessariamente, também um exercício de conversão:

e a isso nos deve encorajar a imagem do homem de Schopenhauer. $O$ homem de Schopenhauer assume sobre si a dor voluntária da veridicidade, e esta dor serve-lhe para matar a sua vontade pessoal e para aprontar a completa inversão e a completa conversão do seu ser [jene völlige Umwälzung und Umkehrung seines Wesens], no seguimento do qual consiste o sentido propriamente dito da vida (SE/Co. Ext. III §4, KSA 1.371).

Uma conversão solitária, que é ao mesmo tempo uma transformação do sujeito e uma formação em liberdade. Na destruição das formas de tirania que o indivíduo traz consigo, ele destrói também a possibilidade de que as tiranias a ele externas possam novamente

29 "indem er für sich die Gegenwart überwindet, auch in seinem Bilde, das er vom Leben giebt, die Gegenwart überwinden...”: SE/Co. Ext. III §3, KSA 1.361. 
Ferraro, G.

afetá-lo. E esta mesma libertação individual, assim como acontecia na antiga parrésia, expõe o filósofo a novos perigos:

onde quer que houvesse uma tirania, ela odiou o filósofo solitário; uma vez que a filosofia confere ao homem um abrigo onde nenhuma tirania pode introduzir-se, a caverna do íntimo, o labirinto do peito, e isto incomoda os tiranos. Lá escondem-se os solitários: mas lá situa-se também o maior perigo para os solitários (SE/Co. Ext. III §3, KSA 1.353-354).

7. De resto, como já Nietzsche tinha sublinhado na Extemporânea sobre a Utilidade e desvantagem da história para a vida, a leitura da história por parte de cada geração pode ser de grande utilidade desde que esta leitura se destine à definição de uma educação que saiba definir regras e formas de vida capazes de assumir a precariedade do "curtíssimo hoje" que aos homens é dado viver. A história, no seu sentido crítico, torna-se, portanto, também exercício, ontologia crítica do presente. Nas palavras de Nietzsche:

Mas que a vida precisa do serviço da história, deve ser entendido de maneira tão clara como a proposição que mais tarde deverá ser demonstrada segundo a qual um excesso de história estraga o ser vivente (HL/Co. Ext. II §2, KSA 1.258).

A história como servidora da vida é contraposta por Nietzsche à história científica dos modernos, evento espiritual que destrói a mesma raiz sobre a qual se desenvolveu: "fiat veritas pereat vita" (HL/Co. Ext. II §4, KSA 1.272). É por isto que a cultura moderna não tem nada de vivo, mas é um "saber em torno de uma cultura" (HL/Co. Ext. II §4, KSA 1.273). E assim como aconteceu com os Gregos, que simplesmente se recusaram a ser os epígonos do Oriente, é preciso fazê-lo agora. Contrapor um sentido histórico ao serviço da vida, um sentido capaz de organizar o caos provocado pelo sentido histórico da ciência moderna: é a partir desta reorganização do caos, logo, a partir de um trabalho crítico sobre a compreensão dos eventos passados ou a partir das "verdadeiras necessidades" (HL/Co. Ext. II

118 Cad. Nietzsche, Guarulhos/Porto Seguro, v.40, n.1, p. 92-123, janeiro/abril, 2019. 
Exercícios de inatualidade. As Considerações extemporâneas como...

$\S 10$, KSA 1.333), que pode surgir uma noção de cultura diferente de uma simples "decoração da vida" (HL/Co. Ext. II §10, KSA 1.333). A crítica do saber histórico contemporâneo torna-se, assim, muito semelhante à crítica da filosofia da III Extemporânea ou à crítica do filisteísmo da I. Aqui trata-se de construir uma autonomia crítica perante os fatos, da mesma maneira que a filosofia é tomada na III a partir dos exempla vita. A "contramodernidade" das Extemporâneas implica uma crítica que é, antes de mais, exercício filosófico, onde a vida é livremente e diretamente soberana do conhecimento.

Evidentemente, estamos longe da época da elaboração de Ecce homo, exemplum de vida filosófica oferecido à posteridade, mas na regula filosófica que podemos aproximar nas Considerações vemos desenvolver-se pela primeira vez uma atitude de pensamento, diretamente ligada à longa tradição dos exercícios espirituais que entra, simultaneamente, dentro da categoria de "ontologia crítica" de Foucault. Uma ontologia prática, "pública", onde o ultrapassar dos limites do sujeito passa pelo ultrapassar das fronteiras da contemporaneidade, como se um não pudesse verdadeiramente acontecer sem o outro.

A filosofia aparece aqui, num momento de viragem crucial para Nietzsche, como prática, e como tarefa. Não é por acaso, por outro lado, que Nietzsche reconhece como a elevação da filosofia acontece precisamente nas épocas em que maior é o perigo para a liberdade e maior a opressão da opinião pública, como no momento em que, em Roma, morre a república e começa a época imperial. E talvez não seja por acaso que Nietzsche reconheça como a maior época filosófica, aquela em que tem mais brilho uma filosofia entendida como maneira de viver, a época estoica e epicureia $(C f$. SE/Co. Ext. III §8, KSA 1.425).

Em conclusão, podemos afirmar que Nietzsche, ou pelo menos uma certa linha do pensamento de Nietzsche, representado neste caso pelas Extemporâneas, traz a possibilidade de o autor ser um 
Ferraro, G.

intérprete consciente, justamente ao falar de inatualidade, da forma crítica da "ontologia da atualidade" que constitui um horizonte filosófico propriamente moderno, e da necessidade, para os modernos, de voltar a uma filosofia constitutivamente ligada à prática de autoconstituição e auto-libertação do sujeito.

Por fim, na última carta da loucura, dirigida a Jacob Burckhardt, carta dramática mais não seja por isto, pela recomposição duma forma lógica da língua, que tem lugar pela última vez precisamente no momento antes de a mesma possibilidade de expressão deixar espaço à sombra, Nietzsche volta a pensar numa altura biográfica crucial, isto é, no seu adeus a Basileia, à forma de vida e de prática filosófica que a Basileia podia representar a partir do abandono do papel público de docente. Trata-se, no fundo, do último pensamento lúcido de Nietzsche. E como justifica Nietzsche aquele abandono e aquela transformação da sua existência, já tão longe no tempo? "Não arrisquei empurrar o meu egoísmo privado até o ponto de negligenciar, por causa disto, a criação do mundo". 30 Nada, na sintaxe desta carta, deixa vazar o silêncio que quase vence a escrita. Então, por que não tomar este texto de forma literal, porque não considerá-lo, mais uma vez, como um segmento de obra filosófica, e de vida, em conjunto? ${ }^{31}$ Quase uma memória fugaz, no momento em que a psiche do autor está a desenvolver-se já sem controle, no caos, a recriação de si é para Nietzsche uma recriação da própria subjetividade face à história e, ao mesmo tempo, uma recriação pública do mundo. Nesse caso "Ser - ou melhor, ter chegado a ser - todos os nomes da história"32 parece ser a consequência lógica da máxima projeção da subjectividade sobre o próprio presente e além deste presente. A partir da identificação, agora quase mágica, da subjetividade com

30 SB/KSA 8.577-578 (Januar 1887 - Januar 1889), An Jacob Burckhardt in Basel, <Turin> 6 Januar 1889.

31 Cf. Roberto Calasso, 2005: pp. 153-202; Luca Lupo, 2011, pp. 463-472.

32 SB/KSA 8.578 (Januar 1887 - Januar 1889), An Jacob Burckhardt in Basel, <Turin> 6 Januar 1889.

$120 \mid$ Cad. Nietzsche, Guarulhos/Porto Seguro, v.40, n.1, p. 92-123, janeiro/abril, 2019. 
a multiplicidade histórica do presente, e a partir de uma prática de transformação de si que coincide com a prática de transformação ou de transvaloração do mundo, no momento em que o devir-si implica, no extremo, um devir-mundo, a tentativa de transformar o mundo dentro de si, onde não se conseguiu transformar o mundo a partir de si, torna-se o êxito extremo do exercício da inatualidade com que Nietzsche tinha iniciado a sua prática filosófica. $\mathrm{O}$ que fracassa em Turim parece, assim, também estar na linha deste exercício, desta prática filosófica: se a recriação do mundo é impossível, talvez seja possível uma recriação do mundo por meio duma recriação de si. Uma absoluta solidão. Lembramos o que escrevia Nietzsche no começo de Ecce homo, quando se interroga sobre o que ele é:

"No fundo, bem se poderia sabê-lo, pois 'não deixei de dar testemunho' de mim próprio. A desproporção entre a grandeza da minha missão e a pequenez dos meus contemporâneos deu, porém, origem a que estes não me ouvissem e nem sequer me vissem” (EH/EH, Prólogo, 1, KSA 6.257).

Na nova maneira que o longo "trabalho" genealógico, ou "autogenealógico" lhe permite, Nietzsche não parece renunciar, no final do seu percurso, à mesma prática de ontologia crítica do presente endereçada anos atrás: talvez a ontologia de todos os nomes da história não seja outra coisa que um esboço, um balbucio de uma forma, redeclinada, da ontologia histórica do presente e da ontologia crítica de si mesmo que emerge nas Extemporâneas. 
Ferraro, G.

\title{
Exercises of Untimeliness. The Untimely Considerations as Critical Ontology
}

\begin{abstract}
Nietzsche's four Untimely Meditations are a set of works generally rather neglected of this author. They are, however, the outcome of a project placed in a critical situation, along the development of Nietzsche as philosopher. By beginning, particularly, with an analysis of the first Meditation, David Strauss, the Confessor and the Writer, and of the third one, Schopenhauer as educator, we will try to show two philosophical perspectives which, launched in the Meditations, will carry Nietzsche's path until its end: the path of an "ontology of the modernity", according with the expression of Foucault, and that of a philosophy as "way of life", according with the expression of Hadot.
\end{abstract}

Keywords: Untimely, critics, modernity, spiritual exercises, Foucault.

\section{Referências}

BATAILLE, Georges. Sobre Nietzsche. Vontade de chance. São Paulo: Autêntica, 2017.

CALASSO, Roberto. Monologo fatale, in NIETZSCHE, Friedrich. Ecce homo. Milano: Adelphi, 2005: pp. 153-202.

CAPUTO, Annalisa (ed.). Rethinking the nietzschean concept of "untimely". Milano: Mimesis, 2018.

COLLI, Giorgio. Dopo Nietzsche. Milano: Adelphi, 1979.

FERRARO, Gianfranco, FAUSTINO, Marta, RYAN, Bartholomew. Os rostos do si. Lisboa: Vendaval, 2019.

FINK, Eugen. La filosofia di Nietzsche. Padova: Marsilio, 1973.

FOUCAULT, Michel. Le gouvernement de soi et des autres II. Cours au Collège de France (1983-1984). Paris: Gallimard, 2008.

FOUCAULT, Michel. Le courage de la vérité. Le gouvernement de soi et des autres II. Cours au Collège de France (1983-1984). Paris: Gallimard, 2009.

122 | Cad. Nietzsche, Guarulhos/Porto Seguro, v.40, n.1, p. 92-123, janeiro/abril, 2019. 
Exercícios de inatualidade. As Considerações extemporâneas como...

FOUCAULT, Michel. Dits et écrits II. 1976-1988. Paris: Gallimard, 2001.

HADOT, Pierre. La philosophie comme manière de vivre. Paris: Albin Michel, 2001.

HADOT, Pierre. Exercises spirituels et philosophie antique. Paris: Albin Michel, 2002.

LUPO, Luca. Appena prima del buio. Le lettere di Nietzsche da Torino. In: CAMPIONI Giuliano, PICA CIAMARRA, Leonardo, SEGALA, Marco. Goethe, Schopenhauer, Nietzsche. Pisa: Ets, 2011, pp. 463-472.

NIETZSCHE, F. Sämtliche Werke. Kritische Gesamtausgabe (KGW). Berlin/New York: Walter de Gruyter, 1967-1978.

NIETZSCHE, F. Sämtliche Briefe: Kritische Studienausgabe (KSB). Berlin/ New York: Walter de Gruyter, 1986.

NIETZSCHE, Friedrich. Ecce homo. Como se chega a ser o que se é. Trad. Paulo Osório de Castro, Lisboa: Relógio d’Água, 2000.

NIETZSCHE, Friedrich. Untimely Meditations. Ed. by D. Breazeale, Cambridge: Cambridge University Press, 2012.

OTTMANN Henning (ed.). Nietzsche Handbuch, Leben-Werk-Wirkung. Stuttgart: Metzler, 2000, pp. 78-86.

PASCHOAL, Antonio Edmilson. Autogenealogia: acerca do "tornar-se que se é". In: "Dissertatio", 42, 2015, pp. 27-44.

PENZO, Giorgio (ed.). Destinazioni. Attualità e inattualità del pensiero di Friedrich Nietzsche. Bologna: Zona, 2001.

REICH, Hauke. Rezensionen und Reaktionen zu Nietzsches Werken: 1872-1889. Berlin-New York: De Gruyter, 2013.

Artigo recebido para publicação em 12/10/2018 Artigo aceito para publicação em 19/12/2018 